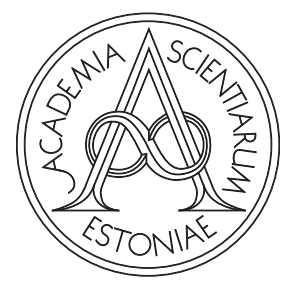

Proceedings of the Estonian Academy of Sciences, $2021, \mathbf{7 0}, 4 \mathrm{~S}, 317-325$

https://doi.org/10.3176/proc.2021.4S.02

Available online at www.eap.ee/proceedings

\title{
The effect of viewing distance on subjective refraction assessment
}

\author{
Alina Kucika*, Ilona Rumjanceva, Tatjana Patrova and Aiga Svede \\ Department of Optometry and Vision Science, Faculty of Physics, Mathematics and Optometry, University of Latvia, Jelgavas iela 1,
} LV-1004, Riga, Latvia

Received 8 November 2020, accepted 10 March 2021, available online 29 September 2021

(C) 2021 Authors. This is an Open Access article distributed under the terms and conditions of the Creative Commons AttributionNonCommercial 4.0 International License (http://creativecommons.org/licenses/by-nc/4.0/).

\begin{abstract}
Accurate detection of subjective refraction is important to provide patients with the best visual quality. One of the factors affecting detection of subjective refraction is viewing distance. Lack of requirements for optometric office arrangement and required space dimensions leads to smaller optometric offices that provide shorter distance between the patient and the optotype chart. However, the effect of decreased viewing distance on detected subjective refraction remains unknown. The aim of this study was to evaluate the effect of viewing distance on the assessment of subjective refraction. Two types of subjective refraction of the dominant eye were determined in 45 participants at five viewing distances $(6 \mathrm{~m}, 5 \mathrm{~m}, 4 \mathrm{~m}, 3 \mathrm{~m}$, and $2.5 \mathrm{~m})$ : subjective refraction that ensured visual acuity 1.0 (in decimal units) and maximum subjective refraction that ensured the best corrected visual acuity. The results demonstrated that viewing distance significantly affected the outcome of subjective refraction detection; there were hyperopic shifts in all types of refractions that increased as the viewing distance decreased. To conclude, the most appropriate viewing distance for subjective refraction detection is $5 \mathrm{~m}$ or $6 \mathrm{~m}$. If viewing distance is reduced to $4 \mathrm{~m}$ or less, a negative spherical lens of the corresponding proximity should be added to the obtained subjective refraction as it cannot be reliably stated that ocular accommodation is fully relaxed. Since this is not always achievable by $0.25 \mathrm{D}$ steps, mirror systems should be used in smaller $(3 \mathrm{~m}$ and closer viewing distances) optometric offices to provide more appropriate subjective refraction detection.
\end{abstract}

Key words: optometry, viewing distance, subjective refraction, optometric office, visual acuity.

\section{INTRODUCTION}

One of the main tasks in optometric practice is to determine subjective refraction with a combination of lenses (spherical and cylindrical components) that provides the best corrected visual acuity at optical infinity with maximally relaxed accommodation (Grosvenor 2007). Based on this finding, the optometrist prepares a prescription for refractive correction (spectacles or contact lenses). Correctly assessed subjective refraction with correctly prescribed correction affects not only vision quality but also helps the optometrist to assess and understand the degree and stability of ocular pathological conditions, changes in visual acuity and the refractive

\footnotetext{
${ }^{*}$ Corresponding author, alina.kuchika@gmail.com
}

state of the eye, especially in patients with progressing eye diseases. In order to ensure the best possible accuracy and repeatability for assessment of subjective refraction, factors affecting the determination of subjective refraction should be considered and identical measurement conditions should be ensured.

The determination of subjective refraction is influenced by internal factors such as accommodation and convergence (Rosenfield and Ciuffreda 1991; Rosenfield et al. 1991; Ciuffreda 2006; Wang and Ciuffreda 2006), pupil diameter and depth of focus (Schwartz and Ogle 1959; Ciuffreda 2006; Wang and Ciuffreda 2006), patient concentration and fatigue (Owens and Wolf-Kelly 1987; Babij et al. 2017) as well as external factors such as the type of optotype chart, contrast and lighting (Ludvigh 1941; Ricci et al. 1998; Chen et al. 2012), room lighting 
(Hecht 1928; Woodhouse 1975; Johnson 1976; Wozniak et al. 1999; Lee et al. 2009; Tidbury et al. 2016), and principles of subjective refraction determination (Sloane et al. 1954; Perrigin et al. 1982; Goss and Grosvenor 1996). Viewing distance is one of the important external factors. Recommendations regarding the distance for subjective refraction detection are uncertain. There are only few sources that discuss the requirements for dimensions of optometric offices to ensure the correct viewing distance. In theory, visual acuity and subjective refraction must be evaluated at optical infinity with maximally limited involvement of accommodation (Grosvenor 2007). Closer distances activate accommodation due to target proximity which is the inverse of the viewing distance. In clinical practice, $6 \mathrm{~m}$ (or $20 \mathrm{ft}$ ) is considered to be "close to optical infinity" with the expected accommodation response $0.17 \mathrm{D}$; the first printed Snellen visual acuity charts were adapted for this viewing distance (Grosvenor 2007). However, Hofstetter (1973) and Visual Functions Committee (1988) presented several arguments on why $4 \mathrm{~m}$ distance is recommended for the assessment of subjective refraction. First, subjective refraction obtained at $4 \mathrm{~m}$ viewing distance can be more easily converted to optical infinity than subjective refraction obtained at $6 \mathrm{~m}$. As theoretical accommodation at $4 \mathrm{~m}$ distance is exactly $0.25 \mathrm{D}$ and detection of subjective refraction proceeds with $0.25 \mathrm{D}$ steps, the subjective refraction should be increased by $0.25 \mathrm{D}$ for myopia but decreased by $0.25 \mathrm{D}$ for hyperopia in order to adapt subjective refraction to optical infinity. Second, most people spend their working days indoors. Therefore, correction at a viewing distance of $4 \mathrm{~m}$ could be more relevant. Standards set by the International Organization for Standardization (ISO 8596:2017) state that the distance between the patient's pupil and the optotype chart should be $4 \mathrm{~m}$ or more. Recalculation of subjective refraction for optical infinity is not mentioned in ISO.

Unfortunately, there are many optometric offices that do not follow any of these requirements; especially the ones located in supermarkets are of smaller dimensions that do not allow appropriate assessment of the patient's refractive state. In 2018 (pilot study, unpublished data), we evaluated the sizes of optometric offices in Latvia and observed that the length varied from $2.80 \mathrm{~m}$ to $5 \mathrm{~m}$. The distance from the patient to the optotype screen ranged between $1.75 \mathrm{~m}$ and $4.40 \mathrm{~m}$. The pilot study demonstrated that visual acuity differed significantly at closer viewing distances, especially in patients with uncorrected myopia. Therefore, we suggested that shorter viewing distances also affect determination of subjective refraction. At shorter viewing distances, accommodation (due to the proximity factor) might be more involved inducing more hyperopic subjective refraction: myopic subjective refraction is expected to become weaker and hyperopic to become stronger. As there is a lack of published studies on this topic, the aim of our study was to evaluate the effect of viewing distance on the assessment of subjective refraction.

Two subjective refraction types were examined at five viewing distances: one refraction that ensured visual acuity 1.0 (in decimal units), and another refraction that ensured the best corrected visual acuity of the participant. We will present research-based arguments for vision specialists on how shorter viewing distances violate correct subjective refraction assessment. This study would determine specific requirements for optometric offices in assessing subjective refraction.

\section{METHOD}

\section{Participants}

The study involved 45 participants aged from 16 to 66 years (mean age $33 \pm 10$ years). The main selection criteria of participants for this study were a corrected visual acuity of the dominant eye at a viewing distance of $6 \mathrm{~m}$ to be at least 1.0 or better (in decimal units) and no presence of structural changes or diseases in the eye. Only participants who knew they had refractive errors were included in the study. Participants with emmetropia (subjective refraction in a range of $\pm 0.25 \mathrm{D}$ ) were not selected.

The study followed the tenets of the Declaration of Helsinki and the approval for the research protocol was obtained from the Ethics Committee of the University of Latvia. All participants signed informed consent after explanation of the study protocol. In the case of children, parental or legal guardian consent was also obtained.

\section{Instruments}

The study was performed in a fully equipped optometrist's working place at the refractive laboratory of the University of Latvia (Department of Optometry and Vision Science). To change the order of the optotypes and eliminate bias in visual acuity assessment, Tomey TCP2000 monitor (ETDRS optotype chart with Sloan letter optotypes; contrast $100 \%$ ) was used. The distance from monitor centre to floor was $1.20 \mathrm{~m}$. The height of the participant's chair was individually adjusted so that the participant's eye level coincided with the area between the centre and the top of the monitor. There were 12 rows on the screen (corresponding to visual acuity from 0.16 to 2.0 in decimal units); each row contained five optotypes (except the first one [0.16 in decimal units] that contained 4 optotypes), and the rows were not isolated during the presentation. The considered row was underlined with a black line. The angular size of optotypes was adjusted to the corresponding viewing distance. 


\section{Procedure}

All measurements for each participant were obtained on the same day from 10 am to $5 \mathrm{pm}$. Constant photopic lighting conditions ( $\sim 200$ lux $)$ were provided throughout the entire procedure. Five viewing distances (from the trial frame plane to the monitor plane) were used: $6 \mathrm{~m}, 5 \mathrm{~m}, 4 \mathrm{~m}, 3 \mathrm{~m}$, and $2.5 \mathrm{~m}$. The sequence of the viewing distances was randomly changed, and the order was recorded in the protocol. Subjective refraction was determined by one person.

To evaluate the effect of pupil size on the obtained data, pupil diameter was measured at each viewing distance before subjective refraction assessment. Pupil size was measured in millimetres with Precision Vision proximity vision card No. 2594. Changes in pupil diameter can affect the depth of focus. If the pupil gets smaller, the depth of focus will increase, decreasing the requirement for accommodation. Thus, patients with smaller pupil diameter could have a smaller effect of shorter viewing distances.

Subjective refraction was assessed monocularly in the dominant eye without cycloplegia. The dominant eye was determined by distance hole-in-the-card test (Rice et al. 2008). Two subjective refraction stages were determined for each participant: subjective refraction which provided visual acuity 1.0 (in decimal units) and maximum subjective refraction which provided the best corrected visual acuity. Subjective (sphero-cylindrical) refraction was assessed using the fogging method (Grosvenor 2007) according to the principle of hyperfocal refraction (the minimum minus for myopia and the maximum plus for hyperopia, which ensures the best corrected visual acuity (Wang and Ciuffreda 2006); the refraction was changed only if it ensured at least three new optotypes that were correctly named by the participant. The subjective refraction was determined by $0.12 \mathrm{D}$ step for spherical component. Cylindrical component was determined by the clock dial test and refined by Jackson's cross cylinder test $( \pm 0.25 \mathrm{D})$.

\section{Statistical analysis}

For data analysis, we used the term 'eyes' instead of participants. To evaluate the effect of viewing distance on the correction of different types of refraction, the participants were analysed in three groups based on the maximum subjective refraction values obtained at $6 \mathrm{~m}$ viewing distance: myopic refraction, hyperopic refraction, and mixed astigmatism. The myopia group (25 eyes) included participants with myopia or myopic astigmatism (one meridian above or equal to $0.50 \mathrm{D}$ in magnitude and the other meridian plano or myopic; the highest spherical component was $-7.37 \mathrm{D}$, average $-2.38 \pm 2.17 \mathrm{D})$. The hyperopia group (14 eyes) included participants with hyperopia or hyperopic astigmatism (one meridian above or equal to $0.50 \mathrm{D}$ in magnitude and the other meridian plano or hyperopic; the highest spherical component was $+7.25 \mathrm{D}$, average $+1.45 \pm 1.79 \mathrm{D})$. The mixed astigmatism group included participants (6 eyes) with subjective refraction $\leq-0.25 \mathrm{D}$ in one meridian and $\geq+0.25 \mathrm{D}$ in the other meridian (the highest spherical component was $+0.75 \mathrm{D}$, average $+0.40 \pm 0.24 \mathrm{D}$, cylindrical component ranged from $-0.50 \mathrm{D}$ to $-3.50 \mathrm{D})$.

No changes in cylindrical component were observed with a decrease in viewing distance. Therefore, only spherical component was analysed. The subjective refraction data obtained at viewing distances of $5 \mathrm{~m}, 4 \mathrm{~m}, 3 \mathrm{~m}$, and $2.5 \mathrm{~m}$ were compared to the data obtained at $6 \mathrm{~m}$ distance (by calculating the difference defined as the refraction shift). The refraction shift was used to demonstrate subjective refraction changes in figures and to compare the effect of refractive type (or pupil size) on changes in subjective refraction. $6 \mathrm{~m}$ distance was chosen as the reference point since it is closer to the concept of optical infinity and is the least affected by ocular accommodation.

To evaluate the effect of pupil size on determined subjective refraction, the participants were divided in three groups based on their pupil diameter at $6 \mathrm{~m}$ viewing distance: $3 \mathrm{~mm}$ (11 eyes), $4 \mathrm{~mm}$ ( 25 eyes), and $5 \mathrm{~mm}$ ( 8 eyes). If the participant had a pupil diameter of $7 \mathrm{~mm}$, the participant's data were excluded from the analysis of pupil size effect.

Statistical analysis was performed using SPSS software and significance was set at a value of $p<0.05$ for all tests. To analyse whether the acquired data corresponded to normal distribution, Shapiro-Wilk test was applied due to the small number of samples (less than 50). Most of the data in general and in the divided groups (subjective refraction and pupil groups) violated the assumption of normal distribution. Therefore, the median and the interquartile range (IQR) were used for data presentation. Friedman test was applied for within-subject data analysis, comparing subjective refraction results at various viewing distances. Post-hoc analysis was performed by means of Wilcoxon signed-rank test with Bonferroni correction to adjust for multiple comparisons in post-hoc analysis. To evaluate the effect of subjective refraction type (and pupil size) on the refraction shifts at various viewing distances, mixed-model ANOVA was used, where subjective refraction groups (and pupil groups) were the between-subjects factor and viewing distance the within-subjects factor.

\section{RESULTS}

\section{The effect of viewing distance on subjective refraction which ensures visual acuity $\mathbf{1 . 0}$}

The results demonstrated that subjective refraction changed statistically significantly at various viewing 
distances (Friedman test: $\left.\chi^{2}(4)=133.4, p<0.001\right)$. Posthoc analysis (with Bonferroni correction, adjusted significance level $p<0.05 / 4=0.0125$ ) was applied with four planned comparisons for subjective refraction at $5 \mathrm{~m}, 4 \mathrm{~m}$, $3 \mathrm{~m}$, and $2.5 \mathrm{~m}$ viewing distances in regard to $6 \mathrm{~m}$ viewing distance (Wilcoxon signed-rank test: $5 \mathrm{~m}: Z=-3.53$, $p<0.001 ; 4 \mathrm{~m}: \mathrm{Z}=-5.42, p<0.001 ; 3 \mathrm{~m}: \mathrm{Z}=-5.61$, $p<0.001 ; 2.5 \mathrm{~m}: \mathrm{Z}=-5.73, p<0.001)$. Subjective refraction at closer distances deviated statistically significantly towards more hyperopic refraction compared to the subjective refraction determined at $6 \mathrm{~m}$ viewing distance: the refraction shift at $5 \mathrm{~m}: 0.12 \mathrm{D}$ (IQR: $0.00 \mathrm{D}$ to $0.13 \mathrm{D}$ ); $4 \mathrm{~m}: 0.13 \mathrm{D}$ (IQR: $0.12 \mathrm{D}$ to $0.25 \mathrm{D}) ; 3 \mathrm{~m}$ : $0.26 \mathrm{D}$ (IQR: $0.25 \mathrm{D}$ to $0.38 \mathrm{D}$ ); $2.5 \mathrm{~m}: 0.38 \mathrm{D}$ (IQR: $0.25 \mathrm{D}$ to $0.50 \mathrm{D}$ ) (Wilcoxon signed-rank test with Bonferroni correction, adjusted significance level $p<0.05 / 6=0.0083$ : all pairwise comparisons $-5.62<\mathrm{Z}<-2.98, p<0.003$ ).

None of the participants showed changes in pupil diameter during the experiment. Mixed model ANOVA demonstrated that the refraction shifts were not related to the participant's pupil sizes at any viewing distance $(F(2,41)=1.19, p=0.32)$.

There were no significant differences in the refraction shifts among the subjective refraction groups at any viewing distance (mixed model ANOVA: $F(2,42)=0.28$, $p=0.76$ ). As the viewing distance decreased, subjective refraction had a statistically significant hyperopic shift in the hyperopia group (Friedman test with Bonferroni correction, adjusted significance level $p<0.05 / 3=0.017$ : $\left.\chi^{2}(4)=36.06, p<0.001\right)$, the myopia group $\left(\chi^{2}(4)=81.37\right.$,

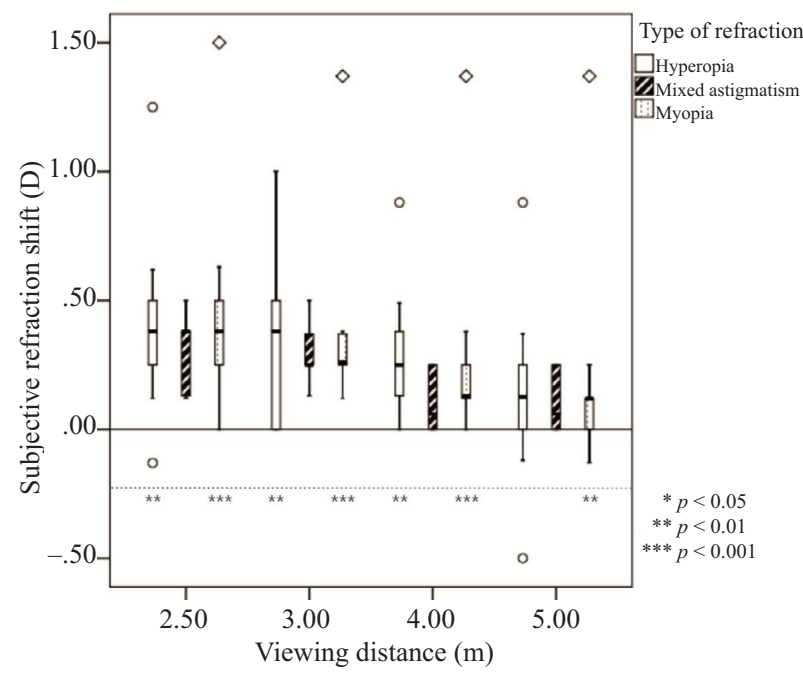

Fig. 1. The refraction shifts (the difference between subjective refraction at $5 \mathrm{~m}, 4 \mathrm{~m}, 3 \mathrm{~m}$, and $2.5 \mathrm{~m}$ distances if compared to subjective refraction at $6 \mathrm{~m}$ distance) for the subjective refraction which ensures visual acuity 1.0 (in decimal units) in three refraction groups: the hyperopia group, the mixed astigmatism group, and the myopia group. Empty rings and diamonds represent outliers. Stars represent data with statistically significant refraction shifts compared to $6 \mathrm{~m}$ viewing distance. $p<0.001)$, and the mixed astigmatism group $\left(\chi^{2}(4)=\right.$ $19.49, p=0.001$ ) (see Fig. 1). In the hyperopia group, no statistically significant differences were detected between the subjective refractions measured at $5 \mathrm{~m}$ and $6 \mathrm{~m}$ viewing distances (Wilcoxon signed-rank test: $Z=-1.88$, $p=0.06$ ), whereas the refraction shifts were statistically significant at other viewing distances (Wilcoxon signedrank test with Bonferroni correction, adjusted significance level $p<0.05 / 4=0.0125: 4 \mathrm{~m}: Z=-3.22, p=0.001 ; 3 \mathrm{~m}$ : $\mathrm{Z}=-2.82, p=0.005 ; 2.5 \mathrm{~m}: \mathrm{Z}=-3.15, p=0.002)$. For the myopia group, the refraction shifts were significantly different at all viewing distances (Wilcoxon signed-rank test with Bonferroni correction, adjusted significance level $p<0.05 / 4=0.0125: 5 \mathrm{~m}: Z=-2.61, p=0.009 ; 4 \mathrm{~m}$ : $\mathrm{Z}=-4.14, p<0.001 ; 3 \mathrm{~m}: \mathrm{Z}=-4.41, p<0.001 ; 2.5 \mathrm{~m}$ : $\mathrm{Z}=-4.30, p<0.001)$. In the mixed astigmatism group, some noticeable refraction shifts were observed only at two viewing distances (3 $\mathrm{m}$ and $2.5 \mathrm{~m}$, see Fig. 1). However, the applied Bonferroni correction (adjusted significance level $p<0.05 / 4=0.0125)$ rejected statistical significance of these refraction shifts $(p=0.026)$.

\section{The effect of viewing distance on maximum subjective refraction}

The analysis of maximum subjective refraction showed statistically significant refraction changes at all viewing distances (Friedman test: $\chi^{2}(4)=113.17, p<0.001$ ) that were not related to pupil sizes (mixed model ANOVA: $F(2,41)=1.02, p=0.37$ ). Post-hoc analysis (with Bonferroni correction, adjusted significance level $p<$ $0.05 / 4=0.0125)$ revealed statistically significant shift towards hyperopia at all viewing distances if compared to $6 \mathrm{~m}$ viewing distance: $5 \mathrm{~m}: 0.00 \mathrm{D}$ (IQR: $0.00 \mathrm{D}$ to $0.13 \mathrm{D}, \mathrm{Z}=-2.60, p=0.009), 4 \mathrm{~m}: 0.25 \mathrm{D}$ (IQR: $0.00 \mathrm{D}$ to $0.25 \mathrm{D}, \mathrm{Z}=-4.90, p<0.001), 3 \mathrm{~m}: 0.25 \mathrm{D}$ ( IQR: $0.12 \mathrm{D}$ to $0.38 \mathrm{D}, \mathrm{Z}=-5.43, p<0.001$ ), $2.5 \mathrm{~m}: 0.37 \mathrm{D}$ (IQR: $0.19 \mathrm{D}$ to $0.50 \mathrm{D}, \mathrm{Z}=-5.56, p<0.001)$. As can be seen from the data, the hyperopic shifts grew at closer viewing distances (Wilcoxon signed-rank test with Bonferroni correction, adjusted significance level $p<0.05 / 6=0.0083$ : all pairwise comparisons $-5.74<\mathrm{Z}<-2.97, p<0.003$ ).

Similar as for the subjective refraction that ensured visual acuity 1.0 , the analysis of maximum subjective refraction shifts demonstrated no difference between the subjective refraction groups at any viewing distances (mixed model ANOVA: $F(2,42)=0.86, p=0.43$ ). Shorter viewing distances produced a hyperopic shift in all refraction groups (Friedman test with Bonferroni correction, adjusted significance level $p<0.05 / 3=0.017$ ): the hyperopia group: $\left.\chi^{2}(4)=28.44, p<0.001\right)$; the myopia group: $\left.\chi^{2}(4)=73.19, p<0.001\right)$, and the mixed astigmatism group $\left(\chi^{2}(4)=15.59, p=0.004\right)$ (see Fig. 2). In the hyperopia group, no statistically significant 


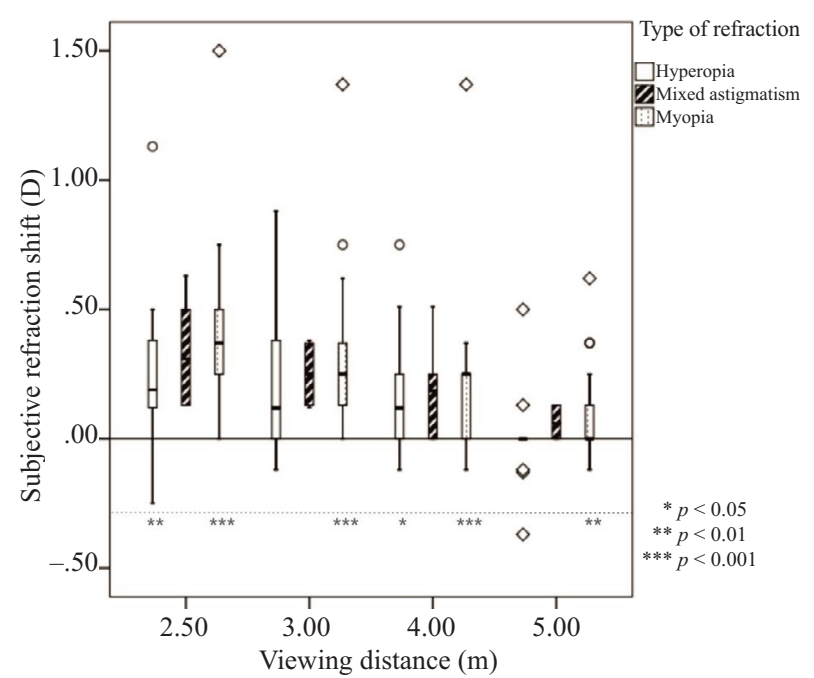

Fig. 2. The refraction shifts (the difference between subjective refraction at $5 \mathrm{~m}, 4 \mathrm{~m}, 3 \mathrm{~m}$, and $2.5 \mathrm{~m}$ distances if compared to subjective refraction at $6 \mathrm{~m}$ distance) for maximum subjective refraction which ensures the best visual acuity in three refraction groups: the hyperopia group, the mixed astigmatism group, and the myopia group. Empty rings and diamonds represent outliers. Stars represent data with statistically significant refraction shifts compared to $6 \mathrm{~m}$ viewing distance.

refraction shifts were observed at $5 \mathrm{~m}$ and $3 \mathrm{~m}$ viewing distances (Wilcoxon signed-rank test with Bonferroni correction: $5 \mathrm{~m}: \mathrm{Z}=0, p=1 ; 3 \mathrm{~m}: \mathrm{Z}=-2.43, p=0.015)$. However, at $4 \mathrm{~m}$ and $2.5 \mathrm{~m}$, the refraction shifts were statistically significant (Wilcoxon signed-rank test with Bonferroni correction: $4 \mathrm{~m}: \mathrm{Z}=-2.57, p=0.01 ; 2.5 \mathrm{~m}: \mathrm{Z}$ $=-2.73, p=0.006$ ). In the myopia group, the maximum subjective refraction shifts were significantly different at all viewing distances (Wilcoxon signed-rank test with Bonferroni correction, adjusted significance level $p<$ $0.05 / 4=0.0125: 5 \mathrm{~m}: \mathrm{Z}=-2.77, p=0.006 ; 4 \mathrm{~m}: \mathrm{Z}=-$ $3.81, p<0.001 ; 3 \mathrm{~m}: \mathrm{Z}=-4.22, p<0.001 ; 2.5 \mathrm{~m}: \mathrm{Z}=$ $-4.32, p<0.001)$. In the mixed astigmatism group, no considerable refraction shifts were observed despite the small tendency towards more hyperopic refraction shifts at $3 \mathrm{~m}$ and $2.5 \mathrm{~m}$ viewing distances $(\mathrm{Z}=-2.21, p=0.027)$.

There was no statistically significant difference between the refraction shifts for the subjective refraction that ensured visual acuity 1.0 and maximum subjective refraction at any of the viewing distances (Wilcoxon signed-rank test $p>0.05$ ) (see Table 1). We compared the detected subjective refraction shifts to theoretical refraction shifts (the theoretical proximity factor difference between each viewing distance and $6 \mathrm{~m}$ viewing distance). No significant differences were detected for $5 \mathrm{~m}$ viewing distance (Wilcoxon signed-rank test with Bonferroni correction, adjusted significance level $\left.p>0.05 / 8=0.006: p_{1.0}=0.007 ; p_{\max }=0.89\right)$. Closer viewing distances showed higher detected refraction shifts compared to the theoretically calculated ones (Wilcoxon signed-rank test with Bonferroni correction $p<0.004)$.

\section{DISCUSSION}

The results demonstrate that viewing distance significantly affects the outcome of the subjective refraction determination. In our study, subjective refraction was determined with the fogging method according to the principle of hyperfocal refraction and by ensuring as little accommodation as possible when viewed at the appropriate distance. This means that if full refractive correction provides the patient with clear vision at optical infinity, then ocular accommodation should operate according to the specified accommodation stimulus at closer distances (proximity factor). Assessing subjective refraction at $4 \mathrm{~m}$, the expected accommodation response would be at least 0.25 D (Hofstetter 1973) or more (Ciuffreda 2006). It follows that the subjective refraction determined at $4 \mathrm{~m}$ distance provides a relaxed position of ocular accommodation, but it is inappropriate to provide clear vision at optical infinity. At $6 \mathrm{~m}$ viewing distance, accommodation corresponds to $0.17 \mathrm{D}$ and the optometrist should decide

Table 1. Various refraction shifts at four viewing distances. Proximity - inverse of the viewing distance. Data for detected subjective refraction shifts are presented as medians

\begin{tabular}{|c|c|c|c|c|}
\hline & \multicolumn{4}{|c|}{ Distance $(\mathrm{m})$} \\
\hline & 5 & 4 & 3 & 2.5 \\
\hline Proximity (D) & 0.20 & 0.25 & 0.33 & 0.40 \\
\hline Theoretical refraction shift from $6 \mathrm{~m}$ (D) & 0.03 & 0.08 & 0.17 & 0.23 \\
\hline \multicolumn{5}{|c|}{ Detected subjective refraction } \\
\hline Refraction shift for visual acuity 1.0 (D) & 0.12 & 0.13 & 0.26 & 0.38 \\
\hline $\begin{array}{l}\text { Refraction shift for maximum subjective } \\
\text { refraction (D) }\end{array}$ & 0.00 & 0.25 & 0.25 & 0.37 \\
\hline Difference between refraction shifts (D) & 0.12 & -0.12 & 0.01 & 0.01 \\
\hline
\end{tabular}


whether to change or not to change the obtained subjective correction to reach optical infinity. Previously, it was presented (Wang and Ciuffreda 2006) that accommodation stimulus and accommodation response coincide only if a target is $1 \mathrm{~m}$ away from the eyes where the accommodation stimulus is 1.00 D. Ciuffreda (2006) explained that the visual system directs the image of the target not precisely on the retinal plane but within the limit of the depth of focus using the minimum required accommodation effort if the object is located at a closer viewing distance. Thus, he explained the accommodation lag. At optical infinity, when accommodation stimulus is zero, an enhanced accommodation response ranging from $0.25 \mathrm{D}$ to $0.33 \mathrm{D}$ is observed (Rosenfield et al. 1991, cited by Ciuffreda 2006). Ciuffreda (2006) concluded that the increased action of accommodation is affected by the depth of focus and tonic accommodation. To keep the target as clear as possible, accommodation works with minimal effort that is required to perceive defined information from the target.

Due to the proximity factor, myopic subjective refraction is expected to become weaker, but hyperopic stronger at shorter viewing distances. Our results confirm this hypothesis; subjective refraction shifted toward hyperopia in all types of refractions. We analysed two subjective refraction stages that showed a similar tendency of the refraction shift. Subjective refraction that enhanced visual acuity 1.0 (in decimal units) allows to compare various individuals better due to normalized visual acuity results. However, clinically the most important is the subjective refraction that allows the best corrected visual acuity (maximum subjective refraction). Both subjective refraction stages demonstrated the same tendency subjective refraction became more hyperopic with shorter viewing distances (see Table 1). Therefore, we will concentrate on the clinically more important stage maximum subjective refraction - in the next paragraphs.

At $5 \mathrm{~m}$ viewing distance, the refraction shift of maximum subjective refraction was not statistically significant for participants with hyperopia and mixed astigmatism. However, in participants with myopia, the refraction shift was statistically significant (IQR for maximum subjective refraction: $0.00 \mathrm{D}$ to $0.13 \mathrm{D}$ ). In optometric practice, this refraction shift is not clinically significant because the minimum step used to determine subjective refraction is $0.25 \mathrm{D}$, which is larger than the detected refraction shift. However, new phoropters allow to determine subjective refraction with a greater precision (smooth power changes in an increment of $0.01 \mathrm{D})$ that could be meaningful in sensitive patients (Marin and Meslin 2020). Marin and Meslin (2020) noticed that about $44 \%$ of patients could distinguish between subjective refraction changes of less than $0.125 \mathrm{D}$. Thus, patients would notice the subjective refraction inaccuracy if shorter (than $6 \mathrm{~m}$ ) viewing distances are used, especially patients with myopia.
Additional studies are needed to evaluate the role of such a small refractive step on visual quality.

At $4 \mathrm{~m}$ distance, statistically significant refraction shifts were observed in the hyperopia and myopia groups, but not in the mixed astigmatism group. These shifts can be considered clinically significant because the maximum subjective refraction shifted by $0.25 \mathrm{D}$ (median; IQR: $0.00 \mathrm{D}$ to $0.25 \mathrm{D}$ ) from the refraction determined at $6 \mathrm{~m}$ viewing distance. Based on the obtained results, a spherical lens of $-0.25 \mathrm{D}$ must be added to the subjective refraction obtained at $4 \mathrm{~m}$ viewing distance in order to equate this subjective refraction with that at $6 \mathrm{~m}$ distance, as well as to ensure good visual acuity at optical infinity. This finding corresponds to the recommendations of Hofstetter (1973) and the Visual Functions Committee (1988) for subjective refraction detection at $4 \mathrm{~m}$ distance.

Increase in hyperopic shifts was observed if closer viewing distances were used (maximum subjective refraction: $0.25 \mathrm{D}[0.12 \mathrm{D}$ to $0.38 \mathrm{D}$ ] for $3 \mathrm{~m}$ and $0.37 \mathrm{D}$ [0.19 D to $0.50 \mathrm{D}]$ for $2.5 \mathrm{~m}$ ). By adding $-0.25 \mathrm{D}$ to the determined maximum subjective correction, some participants at $3 \mathrm{~m}$ viewing distance and most of the participants at $2.5 \mathrm{~m}$ viewing distance would experience an undercorrection. However, by adding $-0.50 \mathrm{D}$, it would be an overcorrection for most participants. If we follow the principle of hyperfocal refraction (Wang and Ciuffreda 2006), the minimum minus or the maximum plus should be determined, which ensures the best visual acuity at optical infinity.

We calculated the theoretical refraction shifts that demonstrated proximity effect differences between $6 \mathrm{~m}$ and closer viewing distances (see Table 1). The detected refraction shifts were higher than the theoretical ones at all viewing distances except at $5 \mathrm{~m}$. Therefore, it cannot be argued that only the proximity factor is involved. Although we used the fogging method to ensure maximally relaxed accommodation, there was higher intersubject variability in refraction shifts at closer distances (see Figs 1 and 2) for both subjective refraction stages. The hyperopia group had increase in inter-subject variability in the refraction shifts that created a border significance at $4 \mathrm{~m}$ and no statistical significance at $3 \mathrm{~m}$ viewing distances for maximum subjective refraction. That could be caused by the strength of accommodation response, which was also noticed by Neroev et al. (2017). They detected that both monocular and binocular accommodation responses were higher in participants with hyperopia compared to participants with myopia.

Thus, assessing subjective refraction at distances equal to or closer than $4 \mathrm{~m}$, it cannot be reliably stated that ocular accommodation is completely relaxed. In cases where optometric offices are too small to ensure appropriate viewing distance for visual acuity assessment and subjective refraction determination at far, mirror 
Table 2. Subjective refraction of two participants (P1 and P2) with the best corrected visual acuity 0.8 (decimal units). They were not included in the overall analysis

\begin{tabular}{l|cc}
\hline $\begin{array}{c}\text { Viewing } \\
\text { distance (m) }\end{array}$ & P1 & P2 \\
\hline 2.50 & +5.75 Dsph -1.00 Dcyl ax $180^{\circ}$ & -7.87 Dsph -0.75 Dcyl ax $180^{\circ}$ \\
3.00 & +5.62 Dsph -1.00 Dcyl ax $180^{\circ}$ & -7.75 Dsph -0.75 Dcyl ax $180^{\circ}$ \\
4.00 & +5.62 Dsph -1.00 Dcyl ax $180^{\circ}$ & -8.00 Dsph -0.75 Dcyl ax $180^{\circ}$ \\
5.00 & +5.62 Dsph -1.00 Dcyl ax $180^{\circ}$ & -8.25 Dsph -0.75 Dcyl ax $180^{\circ}$ \\
6.00 & +5.25 Dsph -1.00 Dcyl ax $180^{\circ}$ & -8.00 Dsph -0.75 Dcyl ax $180^{\circ}$
\end{tabular}

systems are used. Thanks to the optical properties of the mirror, these systems allow to virtually increase the distance between the patient and the screen, ensuring longer viewing distances. However, there is currently a lack of studies on the effect of mirror systems on proximal accommodation and other factors influencing subjective refraction. In future, it would be worth comparing the subjective refractions obtained at real and virtual $6 \mathrm{~m}$ viewing distances.

Although the results of the study showed that changes in subjective refractions were observed in all types of refraction, some differences were noticed. Participants with myopia were the most sensitive to changes in viewing distances. The mixed astigmatism group showed no considerable changes at any of the viewing distances. It can be explained by the small number of participants in the mixed astigmatism group (6 participants). Thus, additional studies would be required to understand better the effect of accommodation on subjective refraction, as well as subjective refraction variations in participants with mixed astigmatism.

Emmetropes were excluded from our study because they have no refractive error at optical infinity. At closer viewing distances, emmetropes could also demonstrate a slight refraction shift in hyperopic direction due to the proximity factor. The effect could be similar as for the hyperopia group because these two groups have similar response to accommodation stimuli. For example, Pandian et al. (2006) described that children with hyperopia and emmetropia demonstrated no difference in accommodative facility at $3 \mathrm{~m}$ distance. However, their accommodative facility was better than in children with myopia. The aforesaid authors examined children $(6.7 \pm 0.4 \mathrm{yr})$ and therefore the data cannot be directly related to our study to predict the behaviour of emmetropes as the age of our participants ranged from 16 to 66 years. O'Leary and Allen (2001) described similar effect in adults aged from 18 to 27 years. They concluded that accommodative facility was higher in the emmetropic group compared to the myopic group. Based on these studies, we could speculate that emmetropes would behave in the same way as hyperopes; they would require hyperopic subjective refraction at closer viewing distances. In future, it would be worth evaluating to what extent and at what significance level emmetropes would be affected by the reduced viewing distances during the eye examination.

Two participants were excluded from the general data analysis due to their reduced visual acuity (it was impossible to reach visual acuity 1.0 in decimal units) at $6 \mathrm{~m}$ distance. However, changes can be observed in their subjective refractions (see Table 2). One participant (P1) had hyperopia with astigmatism and the other (P2) had myopia with astigmatism. Both participants demonstrated hyperopic refraction shifts with decreasing viewing distances. However, the participant with myopia had larger variations in spherical components. In order to corroborate whether the following recommendations on subjective refraction adjustment can be applied to participants with decreased best corrected visual acuity (below 1.0 in decimal units), it would be necessary to evaluate a larger group of participants with decreased best corrected visual acuity.

One of the possible factors that affects subjective refraction detection is pupil diameter. However, our results showed that the hyperopic shift was not related to the pupil size (if it was in a range of 3-5 $\mathrm{mm}$ ). Moreover, no changes in the pupil diameter were observed at any of the viewing distances during the study. This is consistent with the findings by Marg and Morgan (1950); for accommodation stimuli less than $1.00 \mathrm{D}$ (i.e., greater than $1 \mathrm{~m})$, distance had only a minimal effect on the pupil size. In our study, the pupil diameter was assessed with a Precision Vision proximity vision card with a measurement error of $\pm 1 \mathrm{~mm}$. To assess the changes in subjective refraction as a function of pupil diameter with a higher precision, the alternative method of pupil diameter estimation should be used.

\section{CONCLUSIONS}

In general, based on the obtained results, it cannot be stated or denied that $6 \mathrm{~m}$ distance is indeed comparable to the definition of optical infinity. However, it can be 
argued that the subjective refraction determined at $4 \mathrm{~m}$ distance and closer differs significantly from the subjective refraction determined at $6 \mathrm{~m}$ distance. If viewing distance is reduced to $4 \mathrm{~m}$ or less, a negative spherical lens of the corresponding proximity should be added to the obtained subjective refraction as it cannot be reliably stated that ocular accommodation is fully relaxed. Since this is not always achievable by $0.25 \mathrm{D}$ steps, mirror systems should be used in smaller ( $3 \mathrm{~m}$ and closer viewing distances) optometric offices to provide more appropriate subjective refraction detection.

\section{ACKNOWLEDGEMENTS}

We would like to express our gratitude to Gatis Ikaunieks for assistance in preparing the research room. We also wish to thank Varis Karitans for the help in determining the room lighting. Thanks to all study participants who dedicated their time and agreed to participate in the research. The publication costs of this article were partially covered by the Estonian Academy of Sciences.

\section{REFERENCES}

Babij, N. V., Kozyreva, A. A. and Zhukova, E. A. 2017. Daily fluctuations in visual acuity at various distances among students at the Kirov State Medical University. Tendentsii Razvitiya Nauki i Obrazovaniya, 25(3), 30-31 (in Russian).

Chen, A.-H., Norazman, F. N. N. and Buari, N. H. 2012. Comparison of visual acuity estimates using three different letter charts under two ambient room illuminations. Indian J. Ophthalmol., 60(2), 101-104.

Ciuffreda, K. J. 2006. Accommodation, the pupil, and presbyopia. In Borish's Clinical Refraction. 2nd ed. (Benjamin, W. J., ed.), pp. 93-144, Butterworth-Heinemann, Oxford.

Goss, D. A. and Grosvenor, T. 1996. Reliability of refraction a literature review. J. Am. Optom. Assoc., 67(10), 619-630.

Grosvenor, T. P. 2007. Primary Care Optometry. 5th ed. Butterworth-Heinemann/Elsevier, St. Louis, MO.

Hecht, S. 1928. The relation between visual acuity and illumination. J. Gen. Physiol., 11(3), 255-281.

Hofstetter, H. W. 1973. From 20/20 to 6/6 or 4/4? Am. J. Optom. Arch. Am. Acad. Optom., 50(3), 212-221.

ISO 8596:2017 Ophthalmic Optics - Visual Acuity Testing Standard and Clinical Optotypes and Their Presentation.

Johnson, C. A. 1976. Effects of luminance and stimulus distance on accommodation and visual resolution. J. Opt. Soc. Am., 66(2), 138-142.

Lee, E. M., Feis, A. E. and Clark, A. 2009. Effect of room illumination in computerized visual acuity (using smart system II). Optometry, 80(6), 316.
Ludvigh, E. 1941. Effect of reduced contrast on visual acuity as measured with Snellen test letters. Arch. Ophthalmol., 25(3), 469-474.

Marin, G. and Meslin, D. 2020. Refraction: Patients are sensitive to increments smaller than a quarter diopter! Points de Vue: Int. Rev. Ophthalmic Opt., 1-4.

Marg, E. and Morgan, M. W. 1950. Further investigation of the pupillary near reflex; The effect of accommodation, fusional convergence and the proximity factor on pupillary diameter. Am. J. Optom. Arch. Am. Acad. Optom., 27(5), 217-225.

Neroev, V. V., Tarutta, E. P., Arutyunyan, S. G., Khandzhyan, A. T. and Khodzhabekyan, N. V. 2017. Wavefront aberrations and accommodation in myopes and hyperopes. Vestnik Oftalmologii, 133(2), 5-9 (in Russian).

O'Leary, D. J. and Allen, P. M. 2001. Facility of accommodation in myopia. Ophthalmic Physiol. Opt., 21(5), 352-355.

Owens, D. A. and Wolf-Kelly, K. 1987. Near work, visual fatigue, and variations of oculomotor tonus. Investig. Ophthalmol. Vis. Sci., 28(4), 743-749.

Pandian, A., Sankaridurg, P. R., Naduvilath, T., O’Leary, D., Sweeney, D. F., Rose, K. and Mitchell, P. 2006. Accommodation facility in eyes with and without myopia. Investig. Ophthalmol. Vis. Sci., 47, 4725-4731.

Perrigin, J., Perrigin, D. and Grosvenor, T. 1982. A comparison of clinical refractive data obtained by three examiners. Am. J. Optom. Physiol. Opt., 59(6), 515-519.

Ricci, F., Cedrone, C. and Cerulli, L. 1998. Standardized measurement of visual acuity. Ophthalmic Epidemiol., 5(1), 41-53.

Rice, M. L., Leske, D. A., Smestad, C. E. and Holmes, J. M. 2008. Results of ocular dominance testing depend on assessment method. J AAPOS, 12(4), 365-369.

Rosenfield, M. and Ciuffreda, K. J. 1991. Effect of surround propinquity on the open-loop accommodative response. Investig. Ophthalmol. Vis. Sci., 32(1), 142-147.

Rosenfield, M., Ciuffreda, K. J. and Hung, G. K. 1991. The linearity of proximally induced accommodation and vergence. Investig. Ophthalmol. Vis. Sci., 32(11), 29852991.

Schwartz, J. T. and Ogle, K. N. 1959. The depth of focus of the eye. AMA Arch. Ophthalmol., 61(4), 578-588.

Sloane, A. E., Dunphy, E. B., Emmons, W. V. and Gallagher, J. R. 1954. A comparison of refraction results on the same individuals. Am. J. Ophthalmol., 37(5), 696-699.

Tidbury, L. P., Czanner, G. and Newsham, D. 2016. Fiat lux: the effect of illuminance on acuity testing. Graefes Arch. Clin. Exp. Ophthalmol., 254(6), 1091-1097.

Visual Functions Committee. 1988. Visual acuity measurement standard. Ital. J. Ophthalmol., 2(1), 1-15.

Wang, B. and Ciuffreda, K. J. 2006. Depth-of-focus of the human eye: theory and clinical implications. Surv. Ophthalmol., 51(1), 75-85.

Woodhouse, J. M. 1975. The effect of pupil size on grating detection at various contrast levels. Vision Res., 15(6), 645648.

Wozniak, H., Kelly, M., Glover, S. and Moss, N. 1999. The effect of room illumination on visual acuity measurement. Aust. Orthopt. J., 34, 3-8. 


\title{
Vaatamiskauguse mõju subjektiivse refraktsiooni määramisele
}

\begin{abstract}
Alina Kucika, Ilona Rumjanceva, Tatjana Patrova ja Aiga Svede
Subjektiivse refraktsiooni täpne määramine on oluline, et võimaldada patsientidele parimat nägemiskvaliteeti. Üheks mõjutavaks faktoriks subjektiivse refraktsiooni määramisel on vaatamiskaugus. Puudulikud nõuded optomeetria kabineti paigutusele ja vajaliku ruumi mõõtmetele on tekitanud olukorra, kus nägemise uurimise kabinetid pole piisavalt suured ning vaatamiskaugus patsiendi ja optotüübi tabeli vahel on liiga väike. Sellegipoolest ei ole teada lühema vaatamiskauguse mõju subjektiivse refraktsiooni määramisele. Uuringu eesmärk oli teada saada vaatamiskauguse mõju subjektiivse refraktsiooni määramise täpsusele. Domineeriva silma subjektiivne refraktsioon tehti kindlaks kahe meetodiga 45 katseisiku puhul viiel vaatamiskaugusel $(6,5,4,3$ ja 2,5 meetrit): subjektiivne refraktsioon, millega saavutati nägemisteravus 1,0, ja maksimaalne subjektiivne refraktsioon, millega saavutati parim korrigeeritud nägemisteravus. Tulemused osutavad, et vaatamiskaugus mõjutas oluliselt subjektiivse refraktsiooni määramist. Vaatamiskauguse vähenemisel esinesid kõikide refraktsioonivigade korral hüperoopilised muutused. Kokkuvõtteks leiti, et kõige sobivam nägemiskaugus subjektiivse refraktsiooni määramiseks on 5 või 6 meetrit. Kui vaatamiskaugus on 4 meetrit või vähem, siis vastavalt objektide kaugusele tuleks subjektiivse refraktsiooni saavutamiseks kasutada negatiivset sfäärilist läätse, kuna ei saa kindel olla, et silmade akommodatsioon on täielikult lõdvestunud. Kuna selline olukord pole 0,25 D sammude kaupa alati saavutatav, tuleks 3-meetriste ja väiksemate vaatamiskauguste puhul optomeetriakabinetis kasutada peegelsüsteemi, võimaldamaks tõhusamat subjektiivse refraktsiooni määramist.
\end{abstract}

